\title{
Indiccalex: áreas do saber a serviço do estudo da língua
}

\author{
Fabiane Cristina Altino ${ }^{1}$, Celciane Alves Vasconcelos ${ }^{1}$, \\ Cinthyan Renata Sachs C. de Barbosa ${ }^{2}$, Edio Roberto Manfio ${ }^{3}$, \\ Fábio Carlos Moreno ${ }^{4}$, Maria Renata de Mira Gobbo ${ }^{2}$, Marcelo Ozawa de Sousa ${ }^{2}$ \\ ${ }^{1}$ Departamento de Letras Vernáculas e Clássicas - Universidade Estadual de Londrina \\ (UEL) - 86057-970 - Londrina - PR - Brazil \\ ${ }^{2}$ Departamento de Computação - Universidade Estadual de Londrina (UEL) \\ 86057-970 - Londrina - PR - Brazil \\ ${ }^{3}$ Faculdade de Tecnologia de Garça Deputado Júlio Julinho Marcondes de Moura \\ (FATEC) - 17400-000 - Garça - SP - Brazil \\ ${ }^{4}$ Centro de Ciências Tecnológicas - Universidade Estadual do Norte do Paraná (UENP) \\ 86300-000 - Cornélio Procópio - PR - Brazil

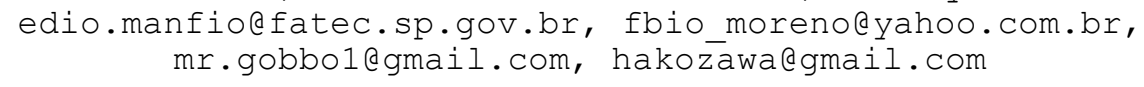

\begin{abstract}
This work describes the Interdisciplinary Project for Dialectology, Computing, Cartography and Lexicography - INDICCALEX. It brings together researchers and professionals from various theoretical and methodological perspectives to meet the wishes of undergraduate and graduate students of the literature course, as well as of researches in the areas involved in this knowledge field from various Higher Education Institutions and it is intended to maintain cooperative agreements with these institutions for the development of projects related to these subareas. This paper will demonstrate a bit about the history of the INDICCALEX, its steps and some of the results achieved.
\end{abstract}

Resumo. Este trabalho descreve o Projeto Interdisciplinar de Dialetologia, Computação, Cartografia e Lexicografia - INDICCALEX. Esse reúne pesquisadores e profissionais de diversas perspectivas teóricas e metodológicas para atender aos anseios dos alunos de graduação e pósgraduação do curso de letras, bem como de pesquisas nas áreas envolvidas neste campo do conhecimento de diversas Instituições de Ensino Superior e tem por objetivo manter acordos de cooperação com essas instituições para o desenvolvimento de projetos relacionados a essas subáreas. Este artigo irá demonstrar um pouco sobre a história do INDICCALEX, seus passos e alguns dos resultados alcançados.

\section{Introdução}

Há algumas décadas, o Departamento de Letras Vernáculas e Clássicas da Universidade Estadual de Londrina (UEL) vem se dedicando ao desenvolvimento de pesquisas 
voltadas para o estudo diacrônico da Língua Portuguesa, tais como: Atlas Linguístico do Paraná - ALPR [Toniolo 2008] [Almeida-Baronas 2013], Atlas Linguístico do Brasil ALiB [Cardoso 2014a] [Cardoso 2014b] [Moreno, Manfio e Barbosa 2017] [Moreno et al. 2015], Tesouro Patrimonial do Léxico Galego e Português [Toniolo 2008] [Almeida Baronas 2013], TEDIPOR, Léxico Histórico do Paraná - LHisPAR [Almeida Baronas 2006] [Almeida Baronas e Almeida 2009] [Company y Melis 2002] e Léxico Histórico do Português Brasileiro - LHisPB, os quais deram origem a um projeto Interdisciplinar de Dialetologia, Computação, Cartografia e Lexicografia - INDICCALEX, que liga-se ao projeto nacional e interinstitucional Para a História do Português Brasileiro - PHPB

Atualmente o Projeto INDICCALEX é desenvolvido na UEL e seu principal objetivo é apresentar, sob tratamento lexicográfico, o conteúdo lexical dos documentos manuscritos datados dos séculos XVII a XIX. Com o avanço da tecnologia, muitos pesquisadores da área da Lexicografia, principalmente aqueles que se dedicam à cartografação de dados linguísticos e toponímicos e à elaboração de glossários e vocabulários precisaram recorrer ao auxílio de novas ferramentas computacionais para a busca, recuperação e indexação de dados linguísticos.

Dessa forma, a proposta do estudo interdisciplinar se justifica pela necessidade da composição de um léxico histórico que possa ser viabilizado por meio de mapas e web, oferecendo um material para estudos sincrônicos e diacrônicos, sob tratamento lexicográfico, apresentando os itens lexicais e suas variantes gráficas vigentes em épocas pretéritas.

O referido trabalho, por ser interdisciplinar, demanda estudos de várias áreas do saber: da Linguística (Dialetologia, Geolinguística, Sociolinguística, Lexicologia e Lexicografia), da Geografia (Cartografia) e da Computação (Processamento de Linguagem Natural, Estrutura de Dados, Processamento de Imagens, Banco de Dados e Engenharia de Software). Para atender aos anseios de cada área de conhecimento, o INDICCALEX

- promove a integração de pesquisadores, docentes e discentes das subáreas supracitadas;

- oferece um espaço para pesquisadores e docentes de várias IES, discute a possibilidade de desenvolvimento de projetos interdisciplinares, interdepartamentais e interinstitucionais com vistas ao avanço do conhecimento científico e tecnológico;

- oferta, sob a forma de banco de dados informatizado, um vasto material lexicográfico para estudos sincrônicos e diacrônicos do léxico registrado em documentos manuscritos durante os três séculos mencionados;

- proporciona um instrumento de consulta rápida do uso de vocábulos vigentes na época e em várias regiões do Brasil Colônia e Brasil Império;

- apresenta, com a frequência de uso, os itens lexicais e suas variantes gráficas registrados em cerca de 2500 documentos emanados das então províncias e vilas sediadas nos atuais estados da Bahia, Rio de Janeiro, São Paulo, Paraná, Minas Gerais, Paraíba, Ceará, Pernambuco e Rio Grande do Sul.

Assim, este artigo mostra na seção 2 a seleção de textos e composição dos corpora para a realização deste trabalho interdisciplinar. A seção 3 apresenta um pouco 
do tratamento lexicográfico e fala sobre a ferramenta computacional. A seção 4 aborda a inserção do site institucional e o analisador léxico desenvolvido. A seção 5 aponta as conclusões e trabalhos futuros.

\section{Seleção de Textos e Composição dos Corpora}

Os 1.394 documentos manuscritos que constituem a base para este trabalho fazem parte do acervo documental maior pertencente às equipes do projeto Léxico Histórico do Português do Brasil, doravante LHiPB, a saber: Léxico Histórico da Bahia - LHisBA (28), Léxico Histórico de Pernambuco - LHisPE (51), Léxico Histórico de São Paulo LHisSP (196), Léxico Histórico da Paraíba - LHisPB (203), Léxico Histórico do Paraná - LHisPAR (730) e Léxico Histórico do Rio de Janeiro - LHisRJ (141).

Para a composição dos corpora foi necessário fazer um recorte inevitável, por não ser possível abarcar tudo o que foi produzido entre os séculos XVII e XIX. Em vista disso, foram selecionados, para a constituição do LHisPB (Léxico Histórico do Português do Brasil), textos de natureza oficial e texto de caráter coloquial (familiar, pessoal). Esta escolha se justifica pelo fato de, observando o corpus constituído de um dos projetos regionais que faz parte do LHisPB, Para a história do português paranaense: estudos diacrônicos em manuscritos dos séculos XVII a XIX, desenvolvido na UEL, a leitura e estudo desses manuscritos têm indicado que, apesar de oficiais (documentos notariais), a ortografia e a gramática ali aplicadas estão longe de ser consideradas a padrão ou de estar rigorosamente dentro da gramática normativa.

O fato acima tem sido atestado por [Toniolo 2008] [Almeida Baronas 2006] [Almeida Baronas e Almeida 2009] em seus estudos, confirmando que, pelo contrário, a forma expressa em muitos dos manuscritos está muito próxima de uma modalidade de língua provavelmente falada por boa parte dos brasileiros no tempo da Colônia e do Império.

Diante da diversidade de gêneros coletados pelas seis equipes (São Paulo, Bahia, Rio de Janeiro, Minas Gerais, Paraná e Paraíba), do grande volume de material já disponível e, tentando compor um corpus geral menos heterogêneo, optou-se por selecionar dois tipos de documentos manuscritos: os oficiais (correspondências eclesiásticas, notariais, cartas ao governo, lista de nomes, relatórios, testamentos, inventários, por exemplo) e os de caráter coloquial (familiar, pessoal, petições, entre outros).

\section{Tratamento lexicográfico: ferramenta computacional}

Finalizada a transcrição e revisão dos 1.394 documentos manuscritos (730 manuscritos paranaenses; 141 fluminenses; 28 baianos, 45 cearenses, 196 paulistas, 51 pernambucanos; 203 paraibanos), a próxima etapa consiste no o tratamento dado aos documentos para a constituição do corpus a ser submetido à ferramenta computacional Lexico3, desenvolvido pela equipe SYLED-CLA2T [Lamalle et al. 2003] [Lexico3, 2019], da Université de La Sorbonne Nouvelle - Paris3. Trata-se de um programa de aplicação lexicométrica que permite:

a) balizar livremente o texto a ser analisado, determinando e distinguindo as partes do texto previamente digitalizado;

b) determinar o tamanho do contexto de um segmento a ser pesquisado; 
c) fazer o levantamento das ocorrências do segmento, indicando a distribuição das palavras dentro do texto;

d) exibir as concordâncias; e

e) apresentar, por meio de gráficos, as frequências relativa e absoluta de uma palavra.

\subsection{Transcrição 1: Tratamento para utilização na ferramenta LEXICO3}

O tratamento para utilização à ferramenta LEXICO3 resume-se em dois procedimentos:

a) Junção e desmembramento de palavras de acordo com a ortografia atual:

- d omesd e Maiod od itto annonesttaVi lla $>$ do mes de Maio do ditto anno nestta Villa;

- pasoaprezente>paso a prezente;

- ese lhes Con staSeja dema conduta >e se lhes Consta Seja de ma conduta

b) Eliminações: da identificação, assinaturas, quebras de linhas, espaços, algarismos, sinais de pontuação.

\subsection{Transcrição 2: tratamento para aplicação à ferramenta LEXICO3}

O tratamento para aplicação à ferramenta LEXICO3 envolve:

Junção de todos os fólios por estado em um só arquivo;

a) Distinção das homógrafas: $\mathrm{a}^{1}=$ artigo, $\mathrm{a}^{2}=$ pronome demonstrativo, $\mathrm{a}^{3}=$ pronome oblíquo, $a^{4}=$ preposição; $a^{5}=$ contração e $a^{6}=$ verbo haver sem o $h$;

b) Passagem para caixa alta, no modelo sem formatação;

c) Submissão ao Programa Lexico3.

Segue abaixo a Figura 1, uma pequena amostragem da ferramenta Léxico 3 que serviu de base para o tratamento do corpus escrito: 


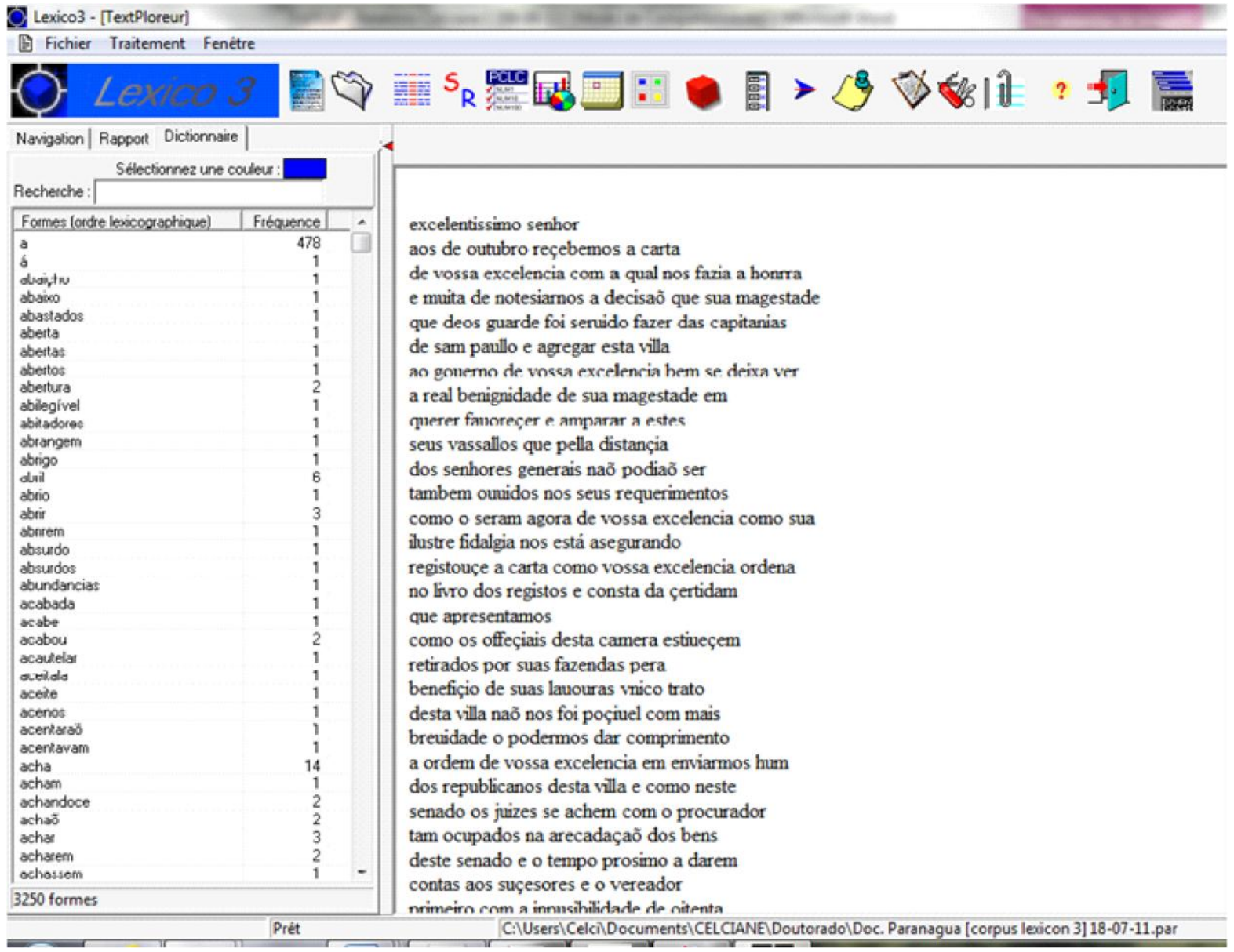

Figura 1. Exemplo de tratamento do corpus escrito: listagem dos vocábulos em ordem alfabética, número de frequência e texto transcrito conforme normas exigidas do programa Lexico3.

\subsection{Construção do verbete}

Os verbetes foram construídos seguindo os moldes da obra de Company y Melis (2002). Ao final do processo, pode-se oferecer um léxico lematizado que corresponde a um dicionário de construção e uso em que as definições semânticas dos lemas não serão incluídas, mas depreendidas pelos contextos das abonações. Assim, o verbete é constituído por:

a) entrada com a norma ortográfica atual;

b) significado(s) no documento;

c) abonação com o local e

d) número do documento, variantes e frequência global.

No LHisPB estão contidos registros de alguns dos usos da língua portuguesa com exemplificação dos diversos contextos gramaticais e semânticos extraídos dos manuscritos, datados dos séculos XVII, XVIII e XIX, editados pelas equipes estaduais do PHPB (São Paulo, Rio de Janeiro, Bahia, Minas Gerais, Paraná, 
Paraíba, além das equipes mais recentes Alagoas, Ceará, Pernambuco e Rio Grande do Sul).

\subsection{Exemplo de verbetes}

Quanto ao modo de apresentar suas características, os verbetes são assim exibidos:

abrimento: Recebemos a Carta que Vossa Excelencia nos derigio datada de 6 de Iunho do prezente anno na qual nos facultava o abrimento do Caminho desta Villa para a Freguezia de Saõ Jozé de Curitiba (GRT, 1805, 198, 03).

FORMAS DOCUMENTADAS: abrimento (1).

FREQUÊNCIA GLOBAL: 1.

adivinhar. quando he sertto que eles camaristas na õ podiam adevinhar o foturo que tal ruina havia de acomteser (CAS, 1805, 736,12).

FORMAS DOCUMENTADAS: adevinhar (1).

FREQUÊNCIA GLOBAL: 1.

mãe. He muito certo que ficaõ desamparadas as Maens destes Orfaons mensionados os quaes por menores naõ se utilizaõ a si nem á suas Maens (CTB, 1799, 81,20); pela esta forma ficaõ dispidas as Mays para vestir os estranhos ficando aquellas em huã total necessidade e desamparo (ANT, 1798, 415, 13).

FORMAS DOCUMENTADAS: maens (3), mays (1).

FREQUÊNCIA GLOBAL: 4.

\section{Analisador Morfológico}

Uma das propostas do INDICCALEX é a inserção dos resultados na página oficial da UEL. Para tanto, este projeto envolve alunos e pesquisadores dos cursos de Letras Vernáculas e Clássicas, Ciência da Computação, Design, além de colaboradores externos. A estrutura do site para o LHisPB está sendo construída conforme a Figura 2.

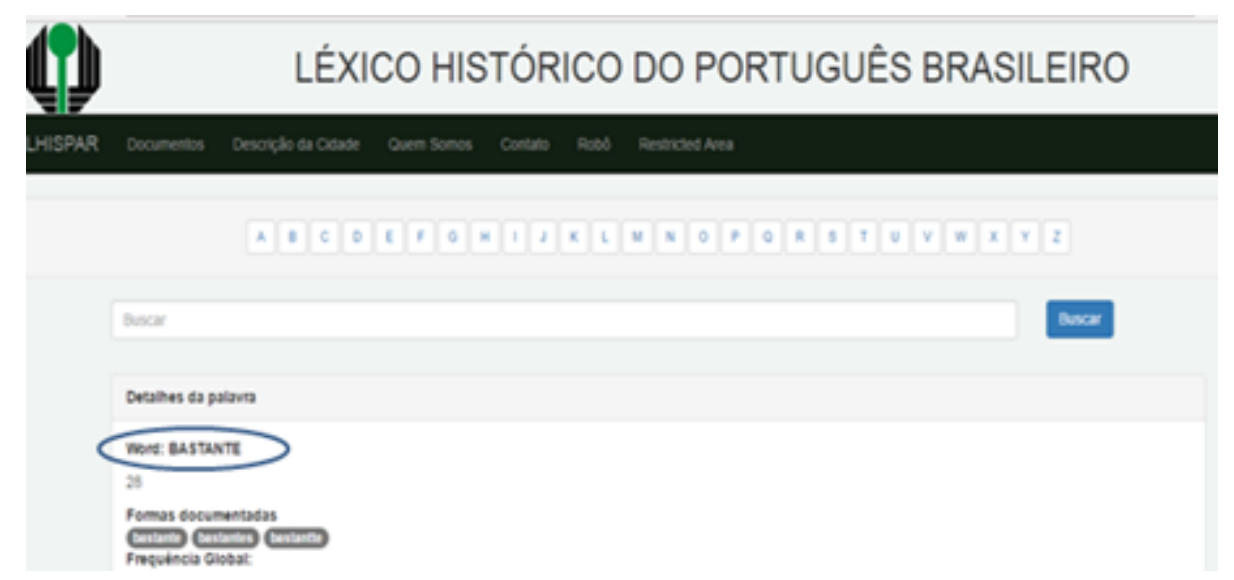

Figura 2. Protótipo do site para o LHisPB

Na página principal há as seguintes informações: (i) logomarca que dá acesso à página principal, (ii) o texto de apresentação, (iii) todos os botões relacionados na Tabela 01, (iv) o campo para digitação de palavras, (v) o campo para exibição dos 
resultados, e (vi) o campo em que figuram as imagens relacionadas e os links para os sites relacionados (UEL, Projeto ALiB, ALPR, parceiros, órgãos de fomento, etc.).

Atualmente a equipe é composta por pesquisadores das seguintes universidades: UEL, FATEC, UNIVEM e UENP. Analisadores Morfológicos foram implementados por discentes na disciplina de Processamento da Linguagem Natural do curso de Ciência da Computação da UEL com o intuito desses alunos fazerem análise morfológica de manuscritos, como nas Figuras 3 e 4.

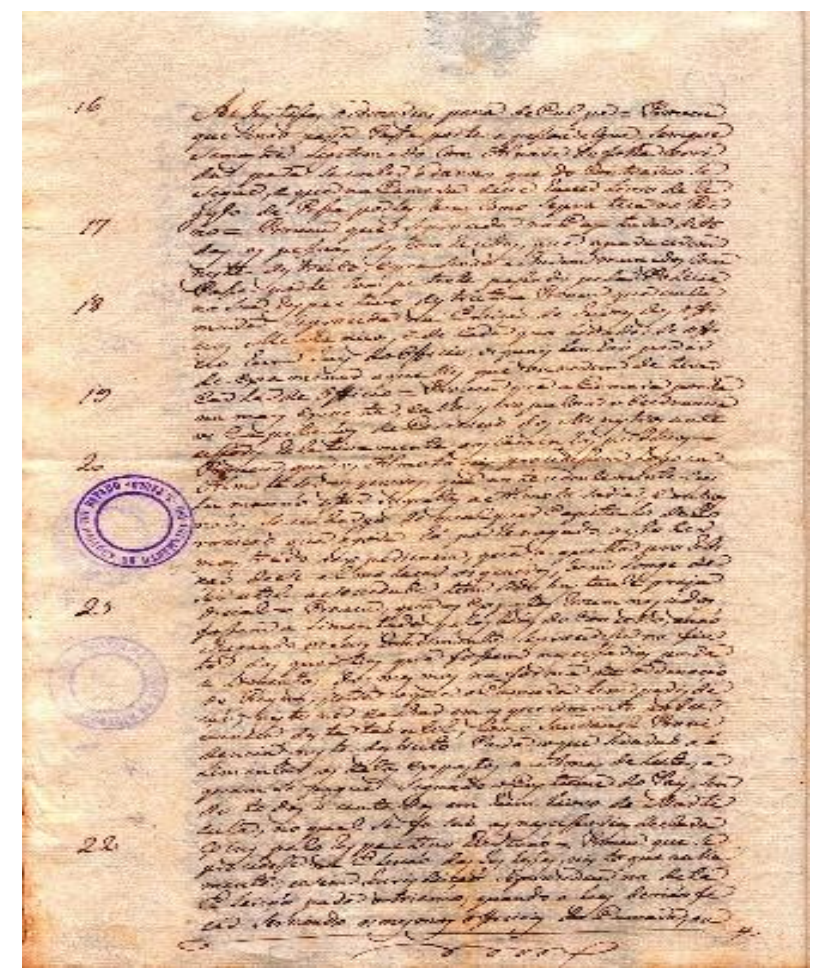

Figura 3. Manuscrito texto 500

\section{Texto do documento 500}

As justissas ordinarias pena de culpa Proveu que senao passe passaporte a pessoa algua sem que se mostre Legitimado com Alvara de folha corrida para se cortar o danno que do contrario se segue e que na Camara deve haver Livro de registo de Passaportes bem como se pratica no Reino Proveu que se proceda na Captura de todas as pessoas desconhecidas que aparecerem neste destricto e que senaõ acharem munidos com Passaporte competente passado pela Policia no seu respectivo destricto Proveu que em Camara se proceda na Eleiçã̃ de Juizes dos officios Mechanicos e de cada qualidade de officio hum Juis do officio os quais tenhaõ poder de examinar aquelles que ouverem de tirar carta de officio Proveu que a Camara ponha na mais exacta e athe escropulosa obcervancia os capitulos de Correiçaõ dos Menistros antecessores relativamente aos caminhos publicos Proveu que os Almotaceis procedessem logo em Almotasar os generos que antecedentemente costumavã̃ estar sugeitos a Almotasaria e outros nã̃ se embargo de qualquer capitulo de Correiçaõ que agora há por revogado visto ter mostrado a experiencia que aquella prohibiçaõ de se almotaçar os generos bem longe de ser util a sociedade tem sido bastante prejudicial Proveu que os expostos recem nascidos fossem alimentados pelos bens do concelho e naõ chegando os seus rendimentos se procedesse na finta das quantias que fossem nescessarias para alimentos dos mesmos na forma da ordenaçã̃ do Reyno para o que a Camara tem jurisdeçã̃ visto ver e achar em esquecimento a obcervancia desta taõ util como saudavel Providencia neste destricto Para o que se daraõ a álimentar os ditos expostos a Amas de Leite a quem se pague segundo o costume do Pais sendo todos acentados em hum livro de Marticula no qual se fasaõ as nescessarias declaraçoins pelo respectivo Escrivaõ Proveu que se procedesse na Eleiçaõ das justissas visto que nullamente e sem jurisdiçã̃ se procedeu na dita Eleiçaõ para o trienio quando alias deviaõ ficar servindo os mesmos officiais da Camara ou 


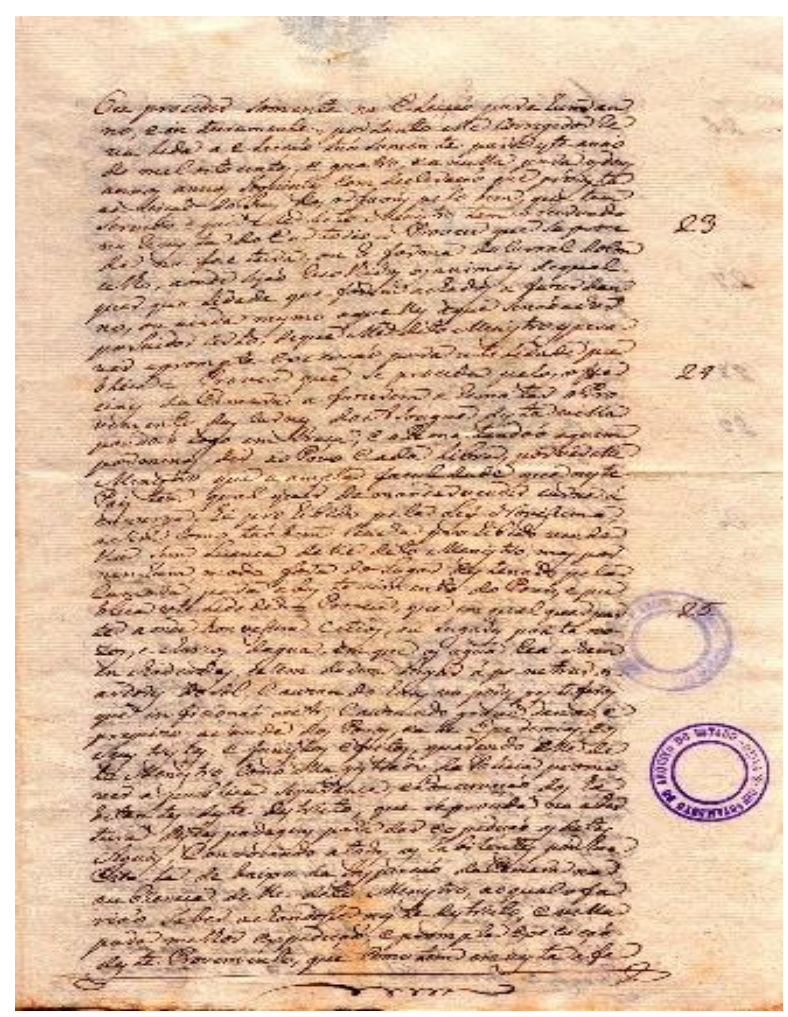

Figura 4. Manuscrito texto 501

\section{Texto do documento 501}

Ou proceder somente na Eleicaõ para hum anno e inteiramente portanto elle corregedor revalida a eLeicão taõ somente para este anno de mil oito centos e quatro e anulla para os dous annos annos seguintes com declaracã que prevista a eleicã̃ do Ju is dos orfaońs pelo bem que tem servido e que elle ditto Menistro tem obcervado na revista do Cartório Proveu que se proceda na factura ou reforma do Curral do Conselho aonde sejao recolhidos os animais de qualquer qualidade que forem achados a fazer Danno ou ainda mesmo aquelles que senã̃ achar possuidor certo de que elle dito Menis tro espera ver aprompta execucã̃ para utilidade publica Proveu que se proceda pelos officiais da Camara a fazerem aRematar o Provimento das carnes do Asougue desta villa pondo-ó logo em praca e arematandoó a quem por menos der ao Povo cada libra por ver elle Menistro que a ampla faculdade que neste Pais tem qualquer demandar vender carne á enxerga hé prohibido pela Ley Novissima asim como taõ bem se acha prohibido vendella sem Licenca delle dito Menistro mas por ninhum modo fora do Lugar destinado pela Camara para abastecimento do povo e publica utelidade Proveu que em qualquer parte aonde houvessem citios ou Lugares pantanozos e charcos dagua em que as agua se achem encharcadas e sem darem Lugar á penetrar os ardores do sol cauzando huns vapores pestiferos que inficionaõ o Ar cauzando grando denno e prejuizo a saude dos povos e ate Epdemias e os seus tristes e funestos efeitos querendo elle dito Menistro como Magistrado da Policia promover a publica seguranca e Concervacã dos habitante por deste destricto que se proceda na abertura destas paragens para dar expedicã̃ as ditas Aguas convocando a todos os habitantes por hua Escala de baixo da Inspencaõ da Camara na aubzencia delle dito Menistro ao qual o fariaõ saber achando se neste districto e villa para melhor expedicã̃ e prompta execucão deste Provimento que como tem em vista a

Importante lembrar que embora não tenha sido projetado para operar exclusivamente com o Lexico3, o analisador morfológico, desenvolvido na linguagem de programação Python (versão 2.7.12), tem a função de selecionar os verbetes já ordenados por aquele software. A comunicação em tempo real do analisador com o website ainda não foi considerada neste trabalho, pois consiste em outra etapa da pesquisa a ser apresentada em momento oportuno. A seguir serão mostradas execuções do parser para várias categorias morfológicas desses textos que serão exibidas nas Figuras de 5 a 10. 


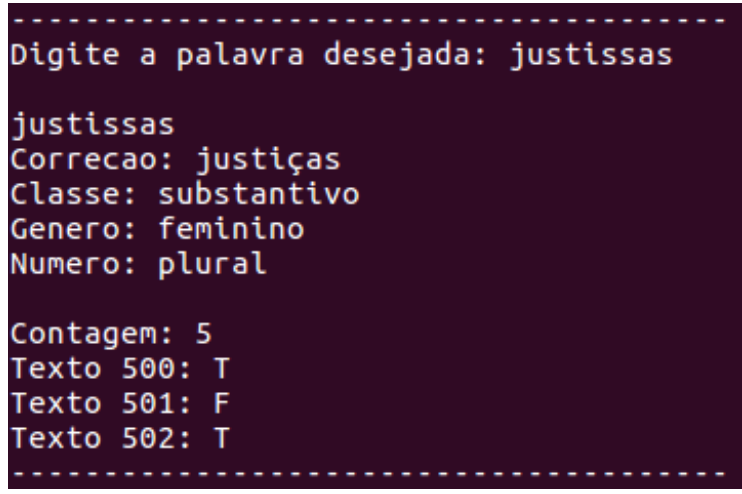

Figura 5. Substantivo justiças

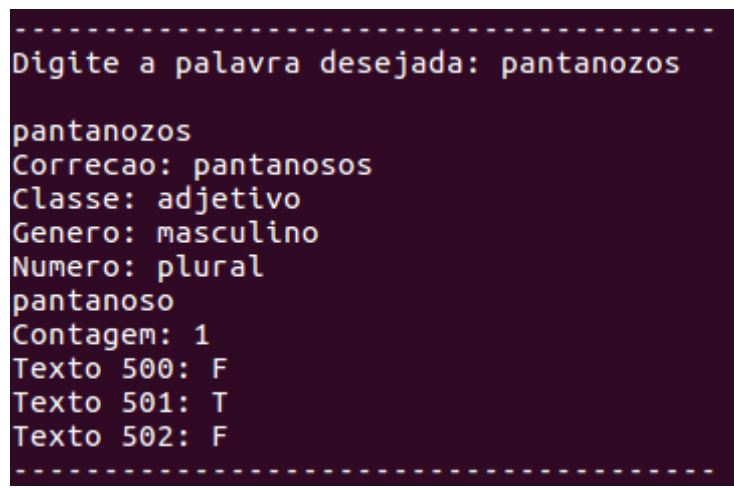

Figura 6. Adjetivo pantanosos

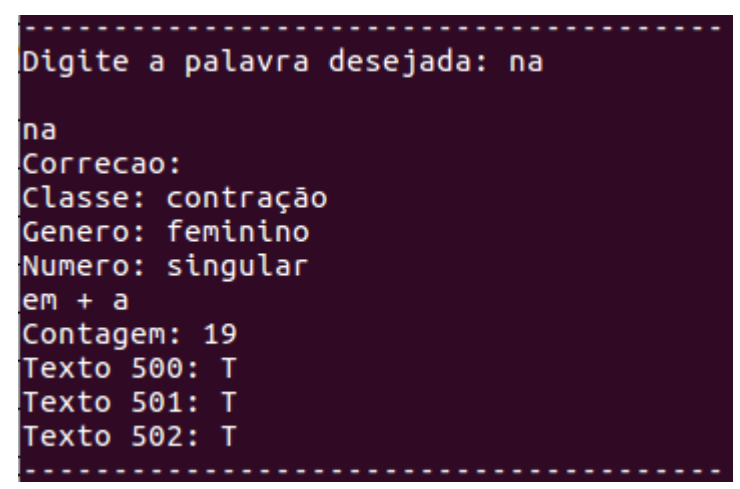

Figura 7. Contração na

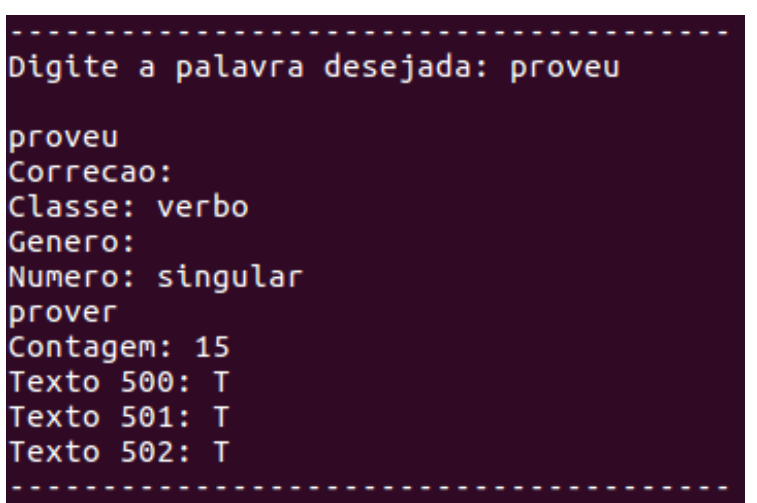

Figura 8. Verbo prover 


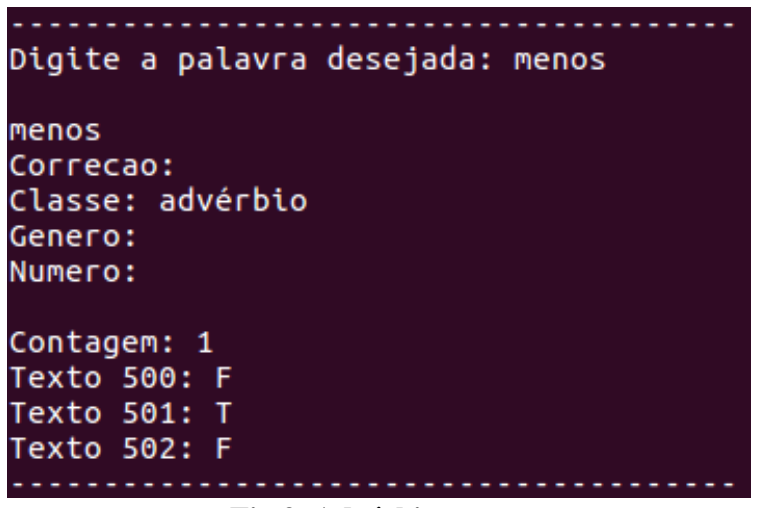

Fig 9. Advérbio menos

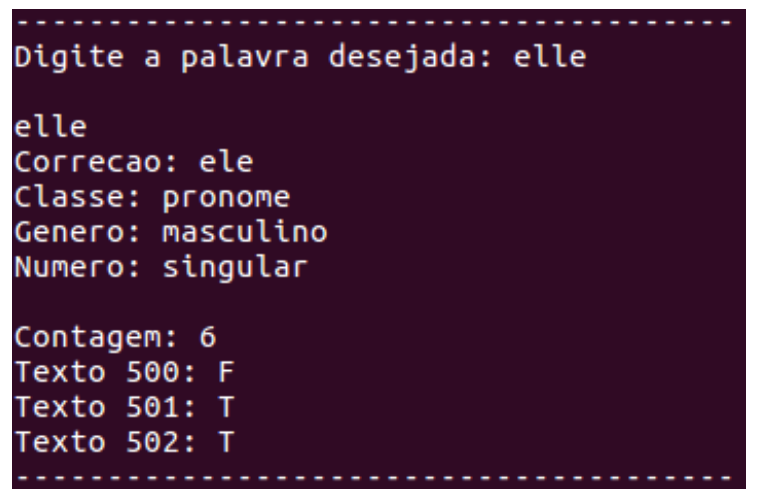

Figura 10. Pronone ele

Note-se que o analisador pode não apenas discriminar as diferentes classes de palavras em português como também extrair delas características gramaticais próprias de sua natureza. Outra vantagem é que não depende da ortografia padrão como ocorre em analisadores convencionais, ou seja, verbetes como 'elle' (grafado com dois 'eles') ou pantanozo (grafado com 'z') não geram inconsistência.

\section{Considerações Finais}

Das etapas realizadas até o momento inclui-se a revisão e confecção de verbetes do Paraná, Rio de Janeiro, Bahia, Paraíba, São Paulo e Pernambuco e os testes com o analisador morfológico. Dentre as metas a serem alcançadas podemos listar: (i) inclusão dos verbetes do Paraná no site LHISPAR, (ii) inclusão dos verbetes dos demais corpora, (iii) incorporação dos verbetes em um que unifique as mesmas entradas. Ex.: officio para os diversos léxicos organizados em uma única entrada (ou agrupados), (iv) melhoria do funcionamento da ferramenta, (v) inclusão de dados nos campos, (vi) inclusão dos fac-símiles no site, (vii) construção do tutorial para a navegação no site, e (viii) transformação do site do LHisPAR em LHisPB.

Acreditamos que o trabalho interdisciplinar traz uma grande contribuição aos estudiosos da área da linguagem que se dedicam aos estudos diacrônicos. A conclusão do Atlas Linguístico do Brasil [Cardoso 2014a] [Cardoso 2014b], é um exemplo disso, pois partes dele já digitalizadas [Moreno, Manfio e Barbosa 2017] [Moreno et al. 2015] constituem material virtual passível de ser consultado por meios puramente digitais e isso tem se estendido a dicionários, glossários e léxicos históricos do português, bem como à elaboração de obras dessa natureza lexicográfica. 


\section{Referências}

Almeida-Baronas, J. E. (2013). Para a História do Português Paranaense. Revista Brasileira de Linguística. Niteroi, 2: pages 207-217.

Almeida-Baronas, J. E. (2006). Manuscritos paranaenses: fontes para um estudo diacrônico. In: V Selisigno e VI Simpósio de Leitura da Universidade Estadual de Londrina. Londrina-PR.

Almeida-Baronas, J. E. e Almeida, P. L. C. de (2009). A escrita dos séculos XVIII e XIX: em busca de dados diacrônicos. In: XIX Seminário do CELLIP - Centro de Estudos Linguísticos e Literários do Paraná. UNIOESTE - Universidade Estadual do Norte do Paraná, Cascavel-PR.

Cardoso, S. A. M. S. et al. (2014a). Atlas Linguístico do Brasil: Introdução, 1. Londrina: Eduel.

Cardoso, S. A. M. S. et al. (2014b). Atlas Linguístico do Brasil: Cartas Linguísticas I, 2. Londrina: Eduel.

Concepción Company e Melis, C. (2002). Léxico histórico del español de México. México: Universidad Autónoma de México.

Lamalle, C., Martinez, W., Fleury, S. and Salem, A. (2003). Lexico 3. http://lexi-co.com/ressources/manuel-3.41.pdf

Lexico3 - SYLED - CLA2T Université de la Sorbonne nouvelle - Paris 3. http: http://lexi-co.com/ressources/manuel-3.41.pdf.

Moreno, F. C., Manfio, E. R. e Barbosa, C. R. S. C. de (2017). Tical: um chatbot que versa sobre assuntos linguísticos. In: $14^{\circ}$ Encontro de Linguística de Corpus, 51.

Moreno, F. C., Manfio, E. R., Barbosa, C. R. S. C. de. e Brancher, J. D. (2015). Tical: Chatbot sobre o Atlas Linguístico do Brasil no WhatsApp. In: $26^{\circ}$ Simpósio Brasileiro de Informática na Educação, Maceió. 1: pages 279-288.

Manfio, E. R., Moreno, F. C. e Barbosa, C. R. S. C. de (2014). Professor Tical e ALiB: Interação Humano Computador em Diferente Campo. In: $19^{\circ}$ Conferência Internacional sobre Informática na Educação, Fortaleza, pages 782-787.

Manfio, E. R., Barbosa, C. R. S. C. e Moreno, F. C. (2016). Um Robô Linguista que "Ouve" e "Fala": Geolinguística, PLN e Tabelas Hash em Concurso. Revista Signum. 19 , pages 415-439.

Toniolo, E. (2008). Possíveis marcas da oralidade em manuscritos paranaenses. In: Filologia e Linguística Portuguesa. FLP 10/11. http: www.fflch.usp.br/ $\mathrm{dlcv/lport/flp/images/arquivos/FLP10-11/Toniolo.pdf}$ 